\title{
Study on the Teaching Mode of Scientific Foreign Language Course under MOOC Background
}

\author{
Huanhuan Ren ${ }^{1, a}$, Chi Ma ${ }^{2, b}$ \\ ${ }^{1}$ Teaching and Research Institute of Foreign Languages, Bohai University, Jinzhou, 121013, China \\ ${ }^{2}$ Jinzhou Institute of Forestry Research, Jinzhou Forestry Bureau, Jinzhou, 121013, China \\ arenhuanhuan2014@163.com, ${ }^{\mathrm{b}}$ machi2014 @tom.com
}

\section{Keywords: Teaching Mode; Scientific Foreign Language; MOOCs}

\begin{abstract}
MOOCs might be exciting in a lot of ways, and the ability of MOOCs to connect experienced professionals with motivated learners is a potent pedagogical combination. It seems obvious that the instruction of English for special purposes is not soundly developed in China since English for general purposes is still grabbing the limelight in foreign language education. It's suggested that three main areas in the teaching mode of scientific foreign language course be considered and stressed under MOOC Background, i.e. filming high quality video lectures, moving towards flipped classroom, and enhancing student-centered learning opportunities, so as to yield better learning outcomes in scientific foreign language learning. It's hoped that this thesis provides a useful reference for future English language education among college students.
\end{abstract}

\section{Introduction}

MOOCs have the potential to change the education landscape, and the patterns and frameworks covered in MOOCs have been used successfully in many domains across the globe. Thus, in what ways will MOOCs transform the higher education landscape, especially pertaining to scientific foreign language learning. Will MOOCs be more likely to provide much value for institutions to cultivate scientific foreign language talents in China? The paper is intended to explore the teaching mode of scientific foreign language course under MOOC background with respect to the review of origin of MOOCs, key characteristics of MOOCs, rationales for MOOCs, and realistic analysis of the scientific foreign language teaching in China. This paper is a summary of this research work, which hopefully provides a useful reference for future scientific foreign language pedagogy among college students.

\section{The Introduction and Background of MOOCs}

Origin of MOOCs. Massive open online courses (abbreviated to MOOCs) are a recent and widely researched development in distance education and the origin of the MOOC goes way back to 2008 when Canadian scholars Stephen Downes and George Siemens of the University of Prince Edward Island led an online course called Connectivism and Connective Knowledge (also known as CCK08)[1]. This course eventually had a whopping 2,200 students enrolled in it as they opened it up, for free, to anyone to participate. Later, Another Canadian educator, Dave Cormier, came up with the term 'MOOC' to describe this new type of education event[2]. As MOOCs have evolved, one co-founder of the first MOOC, Stephen Downes, came up with the terms 'xMOOC' and 'CMOOC' to distinguish between classes modeled on his (cMOOC) and the form (xMOOC) that has become better known since then[3]. Within a cMOOC, learners are encouraged (though not required) to contribute actively, using these digital platforms, however, the truth is that cMOOCs are also not typically sponsored or funded by higher education institutions but are organized by individuals with a passion for a specific content area[4]. In comparison, xMOOC which is offered on university-based platforms are modeled on traditional course materials, learning theories and higher education teaching methods[5]. xMOOCs fit the needs of many (though not all) learners looking for academic courses that meet a specific interest and need[6]. Several top universities - 
such as Harvard, MIT, and Stanford - have begun to offer xMOOCs. The evidence is overwhelming that the Coursera and edX platforms delivered by them have grabbed the spotlight recently.

Key Characteristics of MOOCs. Just like the name indicates, the traits or features of MOOCs can be denoted in three dimensions, i.e. large scale, open access, and online education. These three elements constitute the full picture of what a MOOC may look like. Firstly, the concept of the MOOC is the general idea that the course is aimed at large-scale global participation in learning, or say, with no limit on attendance. That is, a MOOC builds on the active engagement of several hundred to several thousand students who self-organize their participation according to learning goals, prior knowledge and skills, and common interests. It's found that producing and delivering a MOOC at large scale is much different from the courses people have traditionally done in classroom[7]. Secondly, moving toward MOOCs, people have a spirit of openness, which can be seen in many ways. MOOCs are free online courses available to anyone, anywhere in the world with an Internet connection. For instance, early MOOCs often emphasized open-access features, such as open licensing of content, structure and learning goals, to promote the reuse and remixing of resources[8]. Now many universities take the lead in expanding access and making it free. There are a number of major MOOC providers and new entrants who are making inroads into the MOOC market. Lastly, MOOCs is to provide a web-based class environment where effective learning takes place. Taking advantage of new technology to disseminate knowledge is a way to do this. That is, it's about leveraging enabling educational technologies to enhance pedagogy and offer best practices from around the world.

Rationales for MOOCs. MOOCs are theoretically supported by many theories which provide solid rationales for the adoption of MOOCs in education. Above all, it's congruent with the idea of learner autonomy through promoting learners to take control of their learning with more choices and options. Autonomous learning is regarded as the science of the relationship between learners and their learning environment, focusing on the role of learning environment on learners[9]. Learner initiative and responsibilities could be opened up in a more interactive and dynamic environment via the Internet. Moreover, MOOCs allow for multimodal interaction in learning and teaching. Multimodal human-computer interaction refers to "the interaction with the virtual and physical environment through natural modes of communication"[10]. Within a MOOC, the learning involves multimodal interaction with five human senses of learners enabled to be engaged in a more free and natural communication. Lastly, MOOCs support the theory of connectivism, which sees learning as the process of creating connections and expanding or increasing network complexity. What sets connectivism apart from theories such as constructivism is the view that, "learning (defined as actionable knowledge) can reside outside of ourselves (within an organization or a database), is focused on connecting specialized information sets, and the connections that enable us to learn more are more important than our current state of knowing"[11]. MOOCs, especially cMOOCs, are in favor of making connections between work experience, learning, and knowledge, and the role of social and cultural context are emphasized in MOOC learning mode.

\section{Realistic Analysis of the Scientific Foreign Language Teaching in China}

Scientific Foreign Language as English for Special Purposes. Scientific foreign language teaching is typical instruction of English for special purposes (ESP). ESP, in contrast with general English, consists of English language teaching which is designed to meet specified needs of the learner, related in content (i.e. in its themes and topics) to particular disciplines, occupations and activities and centered on the language appropriate to those activities[12]. Notably, there are three reasons common to the emergence of all ESP: the demands of a Brave New World, a revolution in linguistics, and focus on the learner[13]. Specifically speaking, with enormous and unprecedented expansion in scientific, technical and economic activity on an international scale, English now became subject to the wishes, needs and demands of people other than language teachers[14]. Furthermore, revolutionary pioneers in linguistics began to focus on the ways in which language is used in real communication in comparison with traditional linguists which set out to describe the features of language[15]. Lastly, rather than simply focus on the method of language delivery, more 
attention was given to the ways in which learners acquire language and the differences in the ways language is acquired[16]. The final reason as having influenced the emergence of ESP has less to do with linguistics and everything to do psychology[1].

The Development of Scientific Foreign Language Instruction. It seems fairly obvious that the instruction of English for special purposes is not soundly developed in China. As for foreign language teaching, English for general purposes (EGP), other than ESP, is still grabbing the limelight of foreign language education. The guideline for scientific foreign language is totally based on insights gained from developing general English in universities, colleges and schools. Less autonomy and fewer opportunities are given to scholars who are likely to delve into the research and study in scientific foreign language instruction. Just as Nunan claimed, "If teachers are to be the ones responsible for developing the curriculum, they need the time, the skills and the support to do so. The provision of such support cannot be removed and must not be seen in isolation, from the curriculum"[18]. However, this support and provision is insufficient and ineffective whist developing scientific foreign language instruction in China. It sees that people involved in scientific foreign language teaching have nothing to do but comforting with the status quo. Recently, with the advances in multimedia technologies, many instructors introduce multimedia tools into classroom, such as PPT, to enrich pedagogical activities in the process of scientific foreign language teaching. Despite no resistance to technology in any forms, teachers and school leaders often see technological experimentation as outside the scope of their job descriptions.

\section{The Teaching Mode of Scientific Foreign Language Course under MOOC Background}

Filming High Quality Video Lectures. For the MOOCs novice, he or she is supposed to be engaged into typical massive open online course (MOOC) experience through running a MOOC on scientific foreign language. Before running a MOOC, a design should be highly considered through discussion with colleagues and learners. It's advocated that the mode of xMOOC adopted in delivering scientific foreign language course. That is, the new platform launched focuses on a much more traditional course structure typically with a clearly specified syllabus of recorded lectures and quiz-type assessment in scientific foreign language learning. The course content is modeled and prerecorded in video lectures which are posted on the courses' home page so that learners can access them at their pace to complete their learning goals. As xMOOCs are centered around the instructor who is the expert provider of knowledge[19], the interaction part should be highlighted at its maximum within a MOOC, so that learners have the opportunities to ask for assistance and advise on difficult points. Besides the endeavor of language instructors, input from a plethora of campus administrators and staff is needed to review MOOC content, as well as address financial and legal concerns necessary to produce high-quality MOOCs[20]. There is a chance that the course is to teach a class to thousand of learners with joint efforts. To sum up, the move of filming high quality video lectures is a disruptive and evolutive attempt for instructing scientific foreign language under MOOC background.

Moving towards Flipped Classroom. MOOCs give students a sense of their preparedness for stepping into this type of coursework, but that's not enough for learning. Learning involves much more than watching videos-it requires meaningful dialogue between students and teachers to clarify doubts and deepen collective understanding of the material. It's suggested that flipped classroom teaching mode be applied in scientific foreign language course under MOOC background. Flipped classroom is congruent with the idea of MOOC, as it inverts traditional teaching methods through delivering instruction online outside of class and moving homework into the classroom. As Aaron Sams and Jonathan Bergmann states in the book Flip Your Classroom: Reach Every Student in Every Class Every Day, "in this model of instruction, students watch recorded lectures for homework and complete their assignments, labs, and tests in class.[21]” The promise behind flipped classroom is that students are doing the lower levels of cognitive work outside of class, and focusing on the higher forms of cognitive work in class, where they have the support of their peers and instructor[22]. It's evident that flipped classroom added in-person activities to supplement the online experience within MOOCs, through reserving additional class time for collaborative work 
and productive mastery exercises. As it's stated by scholars, it is the interaction and the meaningful learning activities that occur during the face-to-face time that is most important[23], and this is true for scientific foreign language learning under MOOC background.

Enhancing Student-centered Learning Opportunities. MOOCs open up new opportunities for learning to happen in a more student-centric way, especially at scale. Just like scholars states, MOOCs is about a fascinating experiment in the democratization of learning[24]. Learning autonomy should be cultivated among scientific foreign language learners in China. On one hand, learners could still access open courses via the Internet, e.g. MOOCs. Open courses give students a new way to find the best fit and access to academic fields and institutions they may not have previously considered. With the rise of MOOC, the user experience in online learning is greatly improved, especially for its user interface and interactive mode. Perhaps most importantly, learners can engage themselves actively with a whopping number of people who schedule their learning according to learning needs, learning styles and learning contents. This cooperative and communicative experience is conducive to forming an efficient and better autonomous learning actions, as learner autonomy doesn't mean learning independently, but rather learning collectively through connecting with others. On the other hand, autonomous learning can take place independent of the connection of the Internet. Under non-Internet based learning environment, learners can arrange their learning activities autonomously as learners decide how they want to engage with the course and proceed through it. In short, enhancing student-centered learning opportunities shouldn't be underestimated in constructing scientific foreign language under MOOC background.

\section{Summary}

From above, it's concluded that the ability of MOOCs to connect experienced professionals with motivated learners is a potent pedagogical combination. It seems obvious that the instruction of English for special purposes is not soundly developed in China since English for general purposes is still grabbing the limelight in foreign language education. It's suggested that three main areas in the teaching mode of scientific foreign language course be considered and stressed under MOOC Background, i.e. filming high quality video lectures, moving towards flipped classroom, and enhancing student-centered learning opportunities, so as to yield better learning outcomes in scientific foreign language learning. It's hoped that this thesis provides a useful reference for future English language education among college students.

\section{Acknowledgements}

This work is part of the project of On Cultivating and Developing Liaoning Scientific Foreign Language Talents with View to Bourdieu' Theory.. This research was supported by the fund of Liaoning Planning of Philosophy and Social Science (Project No. L16CYY001).

\section{References}

[1][2]Chris Parr. Mooc creators criticise courses' lack of creativity. Times Higher Education, October 2013. Retrieved 1 June 2015.

[3] John Prpić, James Melton, Araz Taeihagh, Terry Anderson. MOOCs and crowdsourcing: Massive courses and massive resources. First Monday. 2015, (12) 20.

[4][5][6] Debbie Morrison. The Ultimate Student Guide to xMOOCs and cMOOCs. Credit Watch. Apr 22, 2013. Retrieved from the information on http : // moocnewsandreviews. Com /ultimateguide-to-xmoocs-and-cmoocso/ \# ixzz4W52uDzeX.

[7][20][24] Douglas C. Schmidt, Zach McCormick. Producing and Delivering a MOOC on Pattern-Oriented Software Architecture for Concurrent and Networked Software. 2013. Retrieved from http://www.dre.vanderbilt.edu/ schmidt/PDF/POSA-MOOC.pdf 
[8]Massive open online course. Retrieved from the information on https://en.wikipedia.org/wiki/Massive_open_online_course

[9]Ren Huanhuan. Connotation and Characteristics of Independent Study with Perspective of Educational Ecology. Journal of Teaching and Management. 2016 (24).

[10]M. L. Bourguet. Designing and Prototyping Multimodal Commands. Proceedings of Human-Computer Interaction (INTERACT'03), 2003, pp. 717-720.

[11] George Siemens. Connectivism: A Learning Theory for the Digital Age. Retrieved from the information on http://www.itdl.org/Journal/Jan_05/article01.htm

[12] Strevens, P. (1988). ESP after twenty years: A re-appraisal. In M. Tickoo (Ed.), ESP: State of the Art (pp. 1-13). Singapore: SEAMEO Regional Centre.

[13] [14] T. Hutchinson, A. Waters. English for Specific Purposes: A learning-centered approach. Cambridge: Cambridge University Press.1987.

[15][16][17] Kristen Gatehouse. Key Issues in English for Specific Purposes (ESP) Curriculum Development. The Internet TESL Journal, Vol. VII, No. 10, October 2001.

[18] D. Nunan. Collaborative language learning and teaching. New York: Cambridge University Press, 1992.

[19] What is the Difference Between xMOOCs and cMOOCs? Retrieved from the information on http://blogs.onlineeducation.touro.edu/distinguishing-between-cmoocs-and-xmoocs/, august, 2013.

[21][23]J. Bergmann, A. Sams. Flip Your Classroom: Reach Every Student in Every Class Every Day. Washington DC: International Society for Technology in Education, 2012.

[22] A. H. Marcus. Flipping the Classroom: Teachers Turn "Homework" on its Head, Educational Technology, May 24, 2012. 